\title{
Diversity of Staphylococcus aureus enterotoxin types within single samples of raw milk and raw milk products
}

\author{
S. Loncarevic ${ }^{1}$, H.J. Jørgensen ${ }^{1}$, A. Løvseth ${ }^{1}$, T. Mathisen ${ }^{1}$ and L.M. Rørvik ${ }^{1,2}$ \\ ${ }^{1}$ Section for Feed and Food Microbiology, National Veterinary Institute, and ${ }^{2}$ Department of Food Safety and Infection Biology, \\ The Norwegian School of Veterinary Science, Oslo, Norway
}

2004/0428: received 16 April 2004, revised 12 August 2004 and accepted 13 August 2004

\begin{abstract}
S. LONCAREVIC, H.J. JøRGENSEN, A. LøVSETH, T. MATHISEN AND L.M. RøRVIK. 2004.
\end{abstract}

Aim: To find out if testing of up to 10 Staphylococcus aureus isolates from each sample from raw milk and raw milk products for staphylococcal enterotoxin (SE) might increase the chances of identifying potential sources of food intoxication.

Methods and Results: Altogether $386 \mathrm{~S}$. aureus isolates were tested for the presence of SE by reversed passive latex agglutination (SET-RPLA), and SE genes (se) by a multiplex polymerase chain reaction (PCR). In 18 of $34(53 \%) S$. aureus positive samples a mixture of $\mathrm{SE}$ and/or se positive and negative isolates were identified. Multiplex PCR increased the number of potential SE producing strains, i.e. isolates that harboured se, with $51 \%$ among the product and $48 \%$ among the raw bovine milk isolates. Examination by pulsed-field gel electrophoresis mostly confirmed clonal similarity among isolates sharing SE/se profile, but did not further differentiate between them.

Conclusions: Isolates of $S$. aureus collected from one sample may show great diversity in SE production and different plating media seem to suppress or favour different strains of $S$. aureus.

Significance and Impact of the Study: Several isolates of $S$. aureus from each sample should be tested for enterotoxin production in cases with typical SE intoxication symptoms with methods that are able to reveal new $\mathrm{SE} / \mathrm{se}$.

Keywords: multiplex PCR, pulsed-field gel electrophoresis, Staphylococcus aureus eneterotoxin, staphylococcal enterotoxin genes, reversed passive latex agglutination.

\section{INTRODUCTION}

Staphylococcus aureus food poisoning is an intoxication caused by ingestion of food containing staphylococcal enterotoxin (SE). It is characterized by an acute onset of nausea, vomiting, abdominal cramps and diarrhoea, and is one of the most common food-borne diseases in the world.

So far, 20 serologically distinct SEs have been identified. SEA, SEB, SEC, SED, SEE (Jones and Khan 1986; Betley and Mekalanos 1988; Couch et al. 1988; Bayles and Iandolo 1989) represent classical types, while SEG, SEH, SEI and

Correspondence to: S. Loncarevic, Section for Feed and Food Microbiology, National Veterinary Institute, PO Box 8156 Dep., 0033 Oslo, Normay (e-mail: Semir.

Loncarevic@vetinst.no).
SEJ are newly described enterotoxins (Ren et al. 1994; Su and Wong 1995; Munson et al. 1998; Zhang et al. 1998). SEC has been described with minor antigenic variations and designated $\mathrm{SEC}_{1}, \mathrm{SEC}_{2}$ and $\mathrm{SEC}_{3}$ (Bergdoll et al. 1965; Avena and Bergdoll 1967; Reiser et al. 1984). Recent studies (Jarraud et al. 2001; Orwin et al. 2001; Letertre et al. 2003; Omoe et al. 2003) have described other SE genes (se); sek, sel, sem, sen, seo, sep, seq, ser and seu) which point to the possible existence of new SE. Not all staphylococci are SE producers, or the amount of produced SE may be insufficient for food intoxication.

The detection of $S$. aureus and $\mathrm{SE}$ in food is often difficult. Food processing may kill the bacteria without destroying the thermostable SE. Methods currently used for 
direct detection of SE in food are enzyme-linked immunosorbent assays. These methods have limitations such as time consumption, cost and a detection limit of SE higher than the level required for staphylococcal intoxication. For presence of $\mathrm{SE}$ in bacterial culture, reversed passive latex agglutination (SET-RPLA) has been the method of choice. The detection limit of this method is $<1 \mathrm{ng} \mathrm{SE} \mathrm{ml}{ }^{-1}$ and it is possible to detect and differentiate the five classical SE (SEA, SEB, SEC and SED) from bacterial isolates.

Sequencing of the genes encoding all the identified SE has given the opportunity for detection and differentiation of all se by the polymerase chain reaction (PCR) technique. The continuous identification of new $\mathrm{SE}$, and the requirement for faster methods in the investigation of food poisoning, have led to the development of methods for simultaneous detection of all se, such as the multiplex PCR technique (Monday and Bohach 1999).

Recently there has been an increase in production and consumption of raw milk products in Norway and consequently increased attention to such products as a potential source of $S$. aureus food poisoning. An outbreak of $S$. aureus intoxication caused by raw milk cheese has been described (Kvellestad et al. 1988), and such products have also caused sporadic cases in Norway (S. Loncarevic, unpublished data). In many suspected staphylococcal food poisoning cases, however, the source for the illness has not been identified, and the number of cases is probably underestimated.

In cases of staphylococcal food poisoning or epidemiological investigations of food, it is common to only test one isolate of $S$. aureus for toxin production. For other bacterial species however, it has been shown that molecular typing and characterization of several isolates from the same food sample, obtained from different plating media, is necessary in order to associate a certain food item with food poisoning (Loncarevic et al. 1996, 1997).

The aim of this study was (i) to find out if testing of up to 10 colonies from each food sample might increase the identification of raw milk and raw milk products as potential sources for staphylococcal intoxication; (ii) to compare results from detection of SE (A-D) by SET-RPLA with the presence of the corresponding se shown by multiplex PCR; (iii) to explore clonal similarity between isolates with various $\mathrm{SE} / \mathrm{se}$ profiles, by comparison of all isolates from one sample by use of restriction enzyme analysis (REA) with pulsedfield gel electrophoresis (PFGE).

\section{MATERIALS AND METHODS}

\section{Isolates of $S$. aureus from raw milk and raw milk products}

Staphylococcus aureus were collected from 26 samples of raw milk products and 18 samples of bovine and caprine bulk milk. The raw milk products were provided by 19 different producers and included fresh, soft, semi-hard and hard cheese from bovine (10), caprine (14) and reindeer (2) milk. Soft cheese included six imported cheese. The milk samples were taken from normal bulk milk at delivery to local dairies. To our knowledge, none of the samples had been involved in food poisoning.

The milk and milk products were analysed for the presence of $S$. aureus. Ten grams of each milk product were added to $90 \mathrm{~g}$ of sterile peptone water and stomached for 30-90 s. Three 10-fold dilutions were made and $0 \cdot 1 \mathrm{ml}$ of each step was inoculated on bovine blood agar (Oxoid, Basingstoke, Hampshire, UK) with washed erythrocytes (BA) and Baird Parker with Rabbit Plasma Fibrinogen supplement $(\mathrm{BP}+\mathrm{RPF})$ (bioMèrieux, Marcy-l'Etoile, France). The plates were incubated for $48 \mathrm{~h}$ at $37^{\circ} \mathrm{C}$. Typical colonies were counted after 24 and $48 \mathrm{~h}$. Typical colonies from both plates were investigated further. Up to five typical and three atypical presumptive $S$. aureus colonies from both blood agar plates and BP-RPF were further investigated. Gram-positive cocci that were catalase and coagulase positive and that exhibited growth on P-agar with $7 \mathrm{mg} \mathrm{l}^{-1}$ acriflavin (Roberson et al. 1992) were considered $S$. aureus.

In total $386 S$. aureus isolates from the raw milk products (209 isolates) and raw bovine (100) and caprine (77) milk were freeze-stored at $-70^{\circ} \mathrm{C}$ in heart infusion broth with $15 \%$ glycerol before further investigation.

\section{SE production test by SET-RPLA}

Up to 10 isolates from each sample were tested for enterotoxin production (SEA to SED) by SET-RPLA assay (Oxoid). The isolates were grown aerobically on blood agar plates for 18-24 h, followed by inoculation into tryptic soya broth (Difco, Detroit, MI, USA) and incubation at $37^{\circ} \mathrm{C}$ for 18-24 h. Testing with SET-RPLA was there after performed according to the manufacturer's instructions.

\section{se identification by multiplex PCR}

Targeting se identification and characterization of the same isolates as tested with SET-RPLA were performed according to the method of Monday and Bohach (1999), with some modifications recommended by Løvseth et al. (2004). After the DNA isolation from overnight growth bacterial culture, amplification of selected $s e$ was obtained by use of 10 primer sets divided into two reaction mixtures (sed, see, seg, sei and $s e a, s e b-s e c, s e c, s e h, s e j)$. DNA was amplified in a MJ Research thermocycler (MJ Research, Waltham, MA, USA) followed by determination of PCR product by electrophoresis and visualization on a UV-transilluminator (Syngene; Syoptics Ltd, Cambridge, UK). Product sizes were estimated using a pUC-mix molecular weight ladder (Fermentas, Vilnius, 
Lithuania). 16S rRNA was used as a control for DNA isolation and presence of bacterial DNA in the PCR reaction.

\section{REA with PFGE}

Isolates tested by SET-RPLA and multiplex PCR from 20 samples were examined for clonal similarity by REA-PFGE. DNA from in situ lysed bacterial cells in chilled agaroseplugs was prepared according to the PulseNet protocol (McDougal et al. 2003). One colony of each $S$. aureus strain was incubated aerobically in brain heart infusion (BHI) broth (Difco) at $37^{\circ} \mathrm{C}$ for $18-24 \mathrm{~h}$. The cells were harvested by centrifugation in a fixed angle rotor at $15000 \mathrm{~g}$ for 3-4 min and after aspiration of the supernatant, the pellet was resuspended in TE-buffer $(10 \mathrm{~mm}$ Tris, $1 \mathrm{~mm}$ EDTA, $\mathrm{pH} 8 \cdot 0$ ). After incubation at $37^{\circ} \mathrm{C}$ in water bath for $\geq 10 \mathrm{~min}$, $1 \mathrm{mg} \mathrm{ml}^{-1}$ Lysostaphin (Sigma-Aldrich) was added to the cell suspension and dispensed into slotformers. Solidified agarose plugs were incubated in a lysis buffer at $37^{\circ} \mathrm{C}$ for at least $4 \mathrm{~h}$ followed by rinsing of plugs with TE buffer for at least four times. Restriction enzyme digestion was carried out using $200 \mu \mathrm{l}$ of digestion buffer containing 30 units of SmaI (Boehringer-Mannheim) enzyme. After enzyme incubation at $30^{\circ} \mathrm{C}$ for at least $3 \mathrm{~h}$, the plugs were placed in $1 \%$ SeaKem Gold agarose (BioWhittaker, Molecular Applications, Rockland, ME, USA) and electrophoresed in a CHEF DR-III-System (Bio-Rad, Richmond, CA, USA). An $19 \mathrm{~h}$ migration period at $200 \mathrm{~V}$ with a pulse time of $5 \mathrm{~s} / 40 \mathrm{~s}$ was used. After running, the gel was treated with ethidium bromide solution (final concentration $1 \mu \mathrm{g} \mathrm{ml}^{-1}$ ) for $20 \mathrm{~min}$ and destained for $45 \mathrm{~min}$ in fresh distilled water. The patterns were visualized with shortwave u.v. light and documented (Syngene; Syoptics Ltd).

\section{RESULTS}

Staphylococcal enterotoxin production and presence of $s e$ in 386 isolates of $S$. aureus obtained from 18 samples of raw milk and 26 samples of raw milk products are shown in Table 1. SE or se were detected in isolates from 10 and 24 $S$. aureus positive samples, respectively, while no SE or se were detected from the remaining eight and two samples respectively. The diversity in SE production and presence of se among the isolates is shown in Tables 2 and 3 .

Twenty-one of the $34(61 \cdot 7 \%)$ samples of raw milk and raw milk products producing SE and/or harbouring se contained a mixture of $S$. aureus isolates that were positive and negative for $\mathrm{SE}$ and/or se. The remaining 23 samples contained isolates that either were all negative for $\mathrm{SE}$ or se (10) or all positive (13).

The greatest diversity of SE types was shown in a sample of imported raw milk soft cheese sample no. 400 (Table 3; Fig. 1).

Table 1 Number of enterotoxin producing Staphylococcus aureus isolates found in raw milk and raw milk cheese by use of SET-RPLA and multiplex PCR

\begin{tabular}{|c|c|c|c|c|c|c|}
\hline \multirow[b]{2}{*}{ Origin } & \multirow{2}{*}{$\begin{array}{l}\text { No. of } \\
\text { samples }\end{array}$} & \multirow{2}{*}{$\begin{array}{l}\text { No. of } \\
\text { isolates }\end{array}$} & \multicolumn{2}{|c|}{$\begin{array}{l}\text { SET-RPLA } \\
\text { (no. of SE) }\end{array}$} & \multicolumn{2}{|c|}{$\begin{array}{l}\text { PCR } \\
\text { (no. of } s e \text { ) }\end{array}$} \\
\hline & & & Samples & Isolates & Samples & Isolates \\
\hline Caprine milk & 8 & 77 & 6 & 51 & 6 & 51 \\
\hline Bovine milk & 10 & 100 & 2 & 12 & 4 & 22 \\
\hline $\begin{array}{l}\text { Raw milk } \\
\text { products }\end{array}$ & 26 & 209 & 13 & 70 & 24 & 142 \\
\hline Total & 44 & 386 & 21 & 133 & 34 & 215 \\
\hline
\end{tabular}

\begin{tabular}{|c|c|c|c|c|c|c|c|c|c|c|c|c|}
\hline \multirow[b]{4}{*}{ Origin } & \multirow[b]{4}{*}{ Samples } & \multicolumn{2}{|c|}{ No. of isolates } & \multirow{2}{*}{\multicolumn{2}{|c|}{$\begin{array}{l}\text { SET-RPLA } \\
\begin{array}{l}\text { No. of positive } \\
\text { isolates }\end{array}\end{array}$}} & \multicolumn{7}{|c|}{ PCR } \\
\hline & & \multirow[b]{3}{*}{ BP-RPF } & \multirow[b]{3}{*}{$\mathrm{BA}$} & & & \multicolumn{7}{|c|}{ No. of positive isolates } \\
\hline & & & & \multirow{2}{*}{$\frac{\mathrm{BP}-\mathrm{RPF}}{\mathrm{SEC}}$} & \multirow{2}{*}{$\frac{\mathrm{BA}}{\mathrm{SEC}}$} & \multicolumn{3}{|c|}{ BP-RPF } & \multicolumn{4}{|l|}{$\mathrm{BA}$} \\
\hline & & & & & & $\sec$ & $\operatorname{seg}$ & sei & $s e b$ & $\sec$ & seg & $s e i$ \\
\hline \multirow[t]{6}{*}{ Caprine milk } & 2394 & 5 & 5 & 4 & & 4 & & & & & & \\
\hline & 2396 & 5 & 5 & 5 & 5 & 5 & & & & 5 & & \\
\hline & 2399 & 5 & 5 & 5 & 5 & 5 & & & & 5 & & \\
\hline & $\mathrm{Sg} 213$ & 5 & 5 & 5 & 5 & 5 & & & & 5 & & \\
\hline & Sg214 & 4 & 5 & 4 & 5 & 4 & & & & 5 & & \\
\hline & Sg215 & 5 & 3 & 5 & 3 & 5 & & & & 3 & & \\
\hline \multirow[t]{4}{*}{ Bovine milk } & 2204 & 5 & 5 & 5 & 5 & 5 & & & & 5 & & \\
\hline & SK254 & 5 & 5 & & & & 1 & 5 & & & 3 & 5 \\
\hline & SK262 & 5 & 5 & & & & & & 1 & & & \\
\hline & SK265 & 5 & 5 & 2 & & 2 & & & & & & \\
\hline
\end{tabular}

Table 2 SE production and se (SE genes) in Staphylococcus aureus isolates obtained from raw milk on BP-RPF and BA, detected by use of SET-RPLA and multiplex PCR 
Table 3 SE production and se (SE genes) in S. aureus isolates obtained from raw milk SET-RPLA and multiplex PCR cheese on BP-RPF and BA detected by use of

\begin{tabular}{|c|c|c|c|c|c|c|c|c|c|c|c|c|c|c|c|}
\hline \multirow[b]{3}{*}{ Cheese sample nos } & \multicolumn{2}{|l|}{$\begin{array}{l}\text { No. of } \\
\text { isolates }\end{array}$} & \multicolumn{3}{|c|}{$\begin{array}{l}\text { SET-RPLA } \\
\text { (no. of positive } \\
\text { isolates) }\end{array}$} & \multicolumn{10}{|c|}{ PCR (no. of positive isolates) } \\
\hline & \multirow[b]{2}{*}{ BP-RPF } & \multirow[b]{2}{*}{ BA } & \multicolumn{2}{|c|}{ BP-RPF } & \multirow{2}{*}{$\frac{\mathrm{BA}}{\mathrm{SEC}}$} & \multicolumn{5}{|c|}{ BP-RPF } & \multicolumn{5}{|c|}{$\mathrm{BA}$} \\
\hline & & & SEC & SED & & $\sec$ & sed & $\operatorname{seg}$ & $s e i$ & sej seh & $s e b$ & $\sec$ & $\operatorname{seg}$ & sei & seh \\
\hline $29-1$ & 5 & 5 & & & & & & 5 & 5 & & & & 1 & & \\
\hline $29-2$ & 5 & 4 & & & & & & 5 & 5 & & & & & & \\
\hline $29-3$ & 5 & 5 & & & & & & 5 & 4 & & & & & & \\
\hline 294 & 5 & 5 & & & & & & 5 & 5 & & & & 2 & & \\
\hline $29-5$ & 5 & 5 & & & & & & 5 & 5 & & & & 1 & & \\
\hline 400 & 5 & 5 & & 1 & & & 1 & 4 & 4 & 1 & 2 & & 2 & & \\
\hline $882-1$ & 5 & 5 & & & 1 & & & & & & & 1 & & & \\
\hline $927-10$ & 5 & 5 & 3 & & 3 & 3 & & & & & & 3 & & & \\
\hline 29 & 3 & 5 & 2 & & 4 & 2 & & & & & & & 4 & & \\
\hline 35 & 5 & 5 & & & & & & & 5 & & & 1 & & 4 & \\
\hline 37 & 3 & 2 & & & & & & & 3 & & & & & 2 & \\
\hline 62 & 5 & 1 & & & & & & 1 & 1 & & & & & & \\
\hline 64 & 5 & 5 & & & & & & & 2 & & & & 3 & 3 & \\
\hline 65 & 5 & 5 & 5 & & 4 & 5 & & & & & & 4 & & & \\
\hline 66 & 1 & 3 & 1 & & 2 & 1 & & & & & & 2 & & & \\
\hline 68 & 0 & 2 & & & 2 & & & & & & & 2 & & & \\
\hline 69 & 5 & 3 & 5 & & 2 & 5 & & & & & & 2 & & & \\
\hline 71 & 3 & 5 & 2 & & 5 & 2 & & & & & & 5 & & & \\
\hline 74 & 2 & 5 & & & & & & & & 2 & & & & & 5 \\
\hline 75 & 5 & 5 & & & & & & 3 & 3 & 2 & & & & & 3 \\
\hline 79 & 1 & 5 & 1 & & 5 & 1 & & & & & & 5 & & & \\
\hline 80 & 4 & 0 & 4 & & & 4 & & & & & & & & & \\
\hline 82 & 0 & 6 & & & 6 & & & & & & & 6 & & & \\
\hline 83 & 4 & 10 & 4 & & 8 & 4 & & & & & & 8 & & & \\
\hline
\end{tabular}

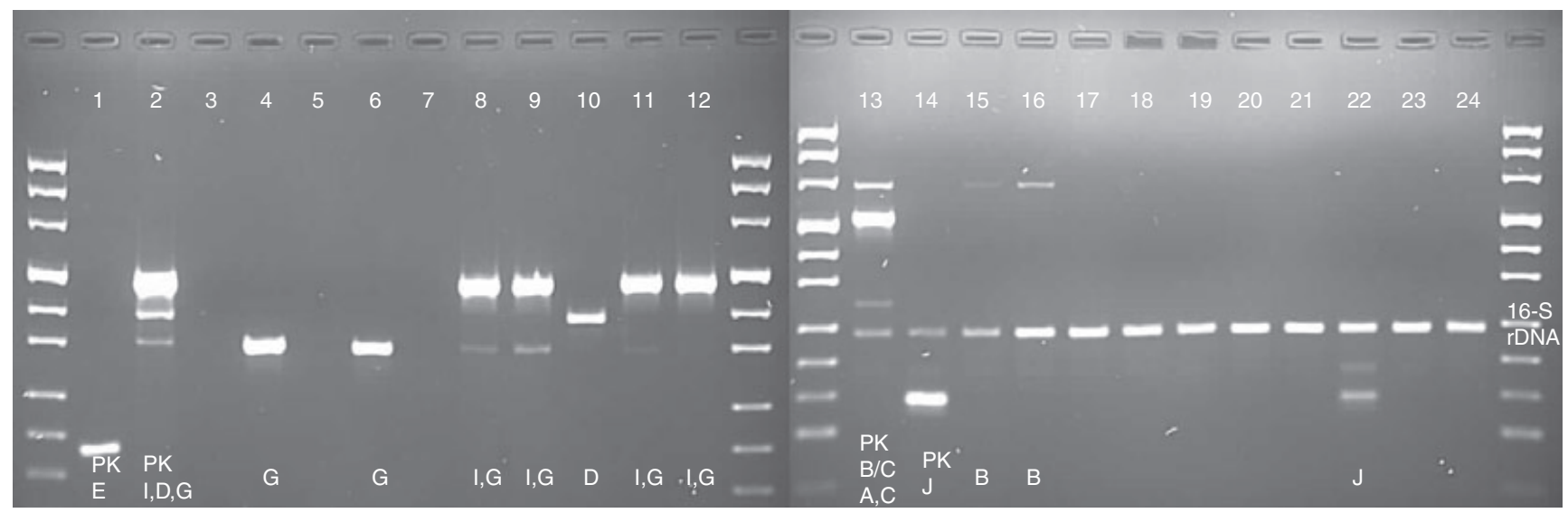

Fig. 1 se genes in $S$. aureus isolates (lines 3-24) from cheese sample no. 400 obtained by multiplex PCR. Lane M marker; lane 1, FRI913 (positive control) see; lane 2, R5010 (positive control) sei, sed, seg; lane 4, isolate nr.319, seg; lane 6, isolate no. 321, seg; lane 8, isolate no. 323, sei, seg; lane 9, isolate no. 324, sei, seg; lane 10, isolate no. 325, sed; lane 11, isolate no. 326, sei, seg; lane 12, isolate no. 327, sei, seg; lane 13, FRI913 (positive control) seb/c, sea, sec; lane 14, R5010 (positive control) sej; lane 15, isolate no. 318, seb; lane 16, isolate no. 319, seb; lane 22, isolate no. 325, sej. Lane 5, isolate no. 320, lane 7, isolate no. 322, no see, sed, seg or sei were detected. Lanes 17-21, 23 and 24, isolates nos 320-324, 326 and 327 , no sea, seb, sec or sej were detected. 16S rDNA, positive control for presence of bacterial DNA in the PCR reaction

(C) 2004 The Society for Applied Microbiology, Journal of Applied Microbiology, 98, 344-350, doi:10.1111/j.1365-2672.2004.02467.x 
The multiplex PCR technique increased the number of potentially $\mathrm{SE}$ positive isolates, i.e. isolates harbouring se with $51 \%$ among the products and $48 \%$ among the raw bovine milk isolates. All except four isolates that harboured classical se also produced the corresponding SE. There was no difference observed between detection of SE and se in isolates from raw caprine milk isolates.

Isolates from 10 raw milk product samples were positive for one or more of the newly described $s e(s e g-s e j)$ without producing classical SEs or harbouring their genes. Among the 122 isolates harbouring new se, seg and sei were predominant (39.3 and $46 \cdot 7 \%)$. Seg and sei in combination were found in $34.4 \%$ of these isolates.

Tables 2 and 3 show various abilities among isolates of $S$. aureus from the same sample to produce SEs or harbour se, related to the method used (SET-RPLA and multiplex PCR), and the agar (BA and BP-RPF) from they were recovered. All these SE positive isolates produced only one 'classical' toxin type, SEC, identified by SET-RPLA and confirmed by multiplex PCR technique (Table 3). Difference between the total number of SE-producing and $s e$-harbouring isolates from all raw milk and raw milk products from BA and
BP-RPF, was not observed. However, isolates with seg and sei in combination were found more often among the isolates obtained from BP-RPF (33) than from BA (10).

By examination of clonal similarity among isolates from 20 samples by REA-PFGE, 14 DNA restriction pattern groups were observed. From single sample, distinguishable patterns were usually identified in isolates containing and not containing $\mathrm{SE}$ and/or se. However, one of five isolates that contained SEC/sec obtained from BP-RPF from a raw caprine milk sample (no. 2396) showed a different DNA restriction pattern from the other four isolates. $S$. aureus isolates that produced SEC and contained sec, obtained from different samples of raw caprine milk (nos 213, 214, 215) and cheeses from raw caprine milk (nos 79, 82 and 83) showed identical DNA restriction patterns. The greatest diversity in DNA restriction patterns was shown among isolates from cheese sample no. 400. Characterization of these 10 isolates by REA-PFGE (Fig. 2) showed that two isolates harbouring $s e g / s e b$ and $s e g$ had identical DNA restriction pattern (clone $\S)$. Four other sei and seg positive isolates, from the same cheese, also displayed identical pattern (clone $\left.f_{0}\right)$. The other isolates were different clones of $S$. aureus.

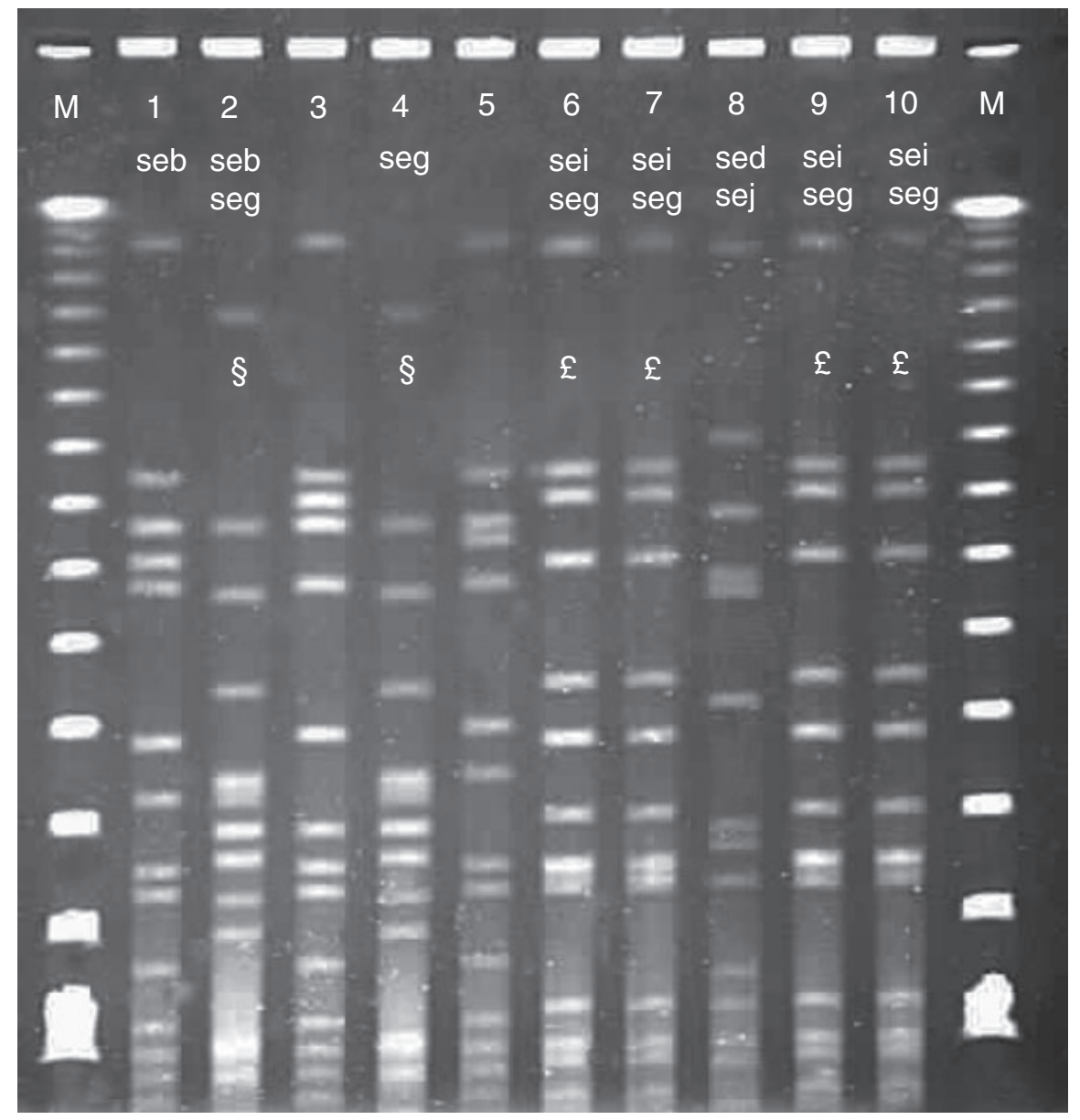

Fig. 2 PFGE profiles of $S$. aureus isolates obtained from cheese sample no. 400. Lane M, Lambda Ladder PFG Marker (BioLabs). Isolates no. 319 producing seg and seb (lane 2) and 321 producing seg (lane 4) had identical DNA restriction patterns (clone §). Isolates nos $323,324,326$ and 327 producing sei and seg (lanes 6, 7, 9 and 10) displayed identical DNA restriction patterns (clone $f_{\text {) }}$ 


\section{DISCUSSION}

Examination of SE production and the presence of se in $S$. aureus isolated from 44 samples of raw milk and raw milk products revealed considerable diversity in the $S$. aureus population both among and within single samples. Altogether $53 \%$ of the samples contained a mixture of SE and/ or se positive and negative isolates. Testing of up to 10 colonies instead of only one from each food sample increased the chance of identifying a potential source of staphylococcal intoxication. In cases where the concentration of an enterotoxin-producing strain of $S$. aureus has been high enough to cause intoxication, the $S$. aureus population in the food item may be less diverse. Examination of only one 'wrong' isolate of $S$. aureus from a suspected food item can, however, lead to missing the source of intoxication. Determination of SE-production and presence of se in several colonies of $S$. aureus from the incriminated food is therefore recommended.

Considerable variation in SE production and presence of $s e$ was observed among the isolates from raw bovine milk and raw milk products. The multiplex PCR technique doubled the number of potentially enterotoxin-producing isolates from these samples compared with SET-RPLA. No difference was observed between $\mathrm{SE}$ and se positive isolates by the two methods among isolates from raw caprine milk, probably because all SE positive isolates produced only one classical toxin type, SEC.

In all isolates where production of classical $\mathrm{SE}$ was identified by SET-RPLA, the presence of se was confirmed by the multiplex PCR technique. In contrast, toxin production indicated by $s e b$ and $s e c$ in four isolates was not verified with SET-RPLA. This finding may be explained by lower sensitivity of the SET-RPLA, or by the fact that detection of $s e$ does not necessarily indicate production and biological activity of the toxin.

As SET-RPLA, which is the most common laboratory method for detection of SEs from bacterial strains, is designed to detect only classical SE (SEA-SED), underestimation of potentially SE producing isolates may be expected. Availability of DNA sequence information of all described se and development of PCR methods has, however, given the opportunity to overcome these problems. In a UK study the incidence of potentially SE-positive isolates increased from 54 to $79 \%$ when this technique was used (McLauchlin et al. 2000). Rosec and Gigaud (2002) observed that the percentage of enterotoxigenic $S$. aureus dramatically increased from 30 to $60 \%$ among the foodborne strains when new se were included in the investigation. As a number of sporadic cases and foodborne outbreaks of staphylococcal intoxication is unsolved, the possibility of $S$. aureus producing new SE in food should be taken in consideration. Other SE than A-D are not yet well characterized, but some of them (SEG, SEH, SEI and $\mathrm{SEJ}$ ) produce emetic reaction in monkeys (Genigeorgis 1989; Bergdoll 1990; Ren et al. 1994) and SEH has already been involved in a food-poisoning case (Pereira et al. 1996).

Isolates from the samples of raw milk products harboured newly described se without producing classical SE types more often (13/24 samples) than isolates from raw milk (one of four samples). McLauchlin et al. (2000) detected se fragments from newly described se in $26 \%$ of 129 se positive isolates without revealing SEA-SED either by PCR or SETRPLA.

A notable finding was that $27.9 \%$ of 215 PCR-positive isolates in our investigation harboured seg and sei genes, while 5.1 and $11.8 \%$ strains harboured seg and sei alone respectively. Rosec and Gigaud (2002) reported that $80.6 \%$ of 155 PCR-positive isolates harboured seg and sei. McLauchlin et al. (2000) observed that over 45 of $129(35 \%)$ isolates harboured $\mathrm{seg}$ and/or $s e i$, while $s e g$ alone was associated with $16 \%$ of incidents. Systematic association of seg and sei genes also observed in this and other studies suggests that they are reservoir or part of a reservoir for enterotoxin gene rearrangement in $S$. aureus (Rosec and Gigaud 2002), as has been hypothesized for the region where sei was identified and sequenced (Munson et al. 1998).

We know from previous studies that one food sample may yield different serovars and clones of the same bacterial species, depending on the method used (Loncarevic et al. 1996). In the present study, one selective (BP-RPF) and one nonselective medium (BA) were employed. The number of $S$. aureus isolates potentially producing classical types of SEs was much higher from BA both with SETRPLA and PCR (42 and 46 respectively) than from BP-RPF (28 and 28). In contrast, the selective medium revealed a higher number of isolates harbouring new se (96) than BA (26). The indication that certain strains of a bacterial species may be suppressed or favoured by different media is in agreement with the statement of Lewis and Corry (1992) and Loncarevic et al. (1996). To prevent that a causative $S$. aureus is missed, it is important to examine colonies from different media in a case of staphylococcal intoxication.

In the present study, 10 samples contained $S$. aureus isolates with two to six different $\mathrm{SE} / \mathrm{se}$ profiles and up to six different REA-PFGE patterns. In one raw milk product sample (no. 400) the 10 isolates showed six different se profiles (seb, sed, sei, seg, sej and combinations), while only one isolate produced SE (SED). Except for two isolates harbouring $s e g / s e b$ and $s e g$ showing identical DNA restriction pattern, isolates with the same toxin profile shared identical PFGE patterns, and those with different toxin profiles also yielded different patterns. It was not surprising that a cheese sample showed the highest diversity of $S$. aureus as the potential sources of bacterial contamination 
of raw milk cheese are multiple; raw milk possibly from several farms, the processing environment and personnel.

In conclusion, several isolates of $S$. aureus should be tested for enterotoxin production in cases where typical symptoms of SE intoxication are observed. Different plating media seem to suppress or favour different strains of $S$. aureus. Methods with ability to reveal new se (G-J), such as multiplex PCR, should be used in solving food poisoning cases. REA-PFGE mostly confirmed clonal similarity among isolates sharing $\mathrm{SE} /$ se profile and did not further differentiate between them.

\section{ACKNOWLEDGEMENTS}

This work was supported financially by the Nordic Council of Ministers and the Norwegian Research Council (Grant no. $141197 / 130)$ to whom we express our gratitude.

\section{REFERENCES}

Avena, R.M. and Bergdoll, M.S. (1967) Purification and some physicochemical properties of enterotoxin C, Staphylococcus aureus strain 361. Biochemistry 6, 1474-1480.

Bayles, K.W. and Iandolo, J.J. (1989) Genetic and molecular analyses of the gene encoding staphylococcus enterotoxin D. Fournal of Bacteriology 171, 4799-4806.

Bergdoll, M.S. (1990) Staphylococcal food poisoning. In Foodborne Infections and Intoxications ed. Riemman, H. and Bryan, F.L. pp. 85106. New York: Academic Press.

Bergdoll, M.S., Borja, C.R. and Avena, R.M. (1965) Identification of new enterotoxin as eneterotoxin C. Fournal of Bacteriology 90, 14811485.

Betley, M.J. and Mekalanos, J.J. (1988) Nucleotide sequence of the type A staphylococcal enterotoxin gene. Fournal of Bacteriology 170, 34-41.

Couch, J.L., Soltis, M.T. and Betley, M.J. (1988) Cloning and nucleotide sequence of the type $\mathrm{E}$ staphylococcus enterotoxin. Journal of Bacteriology 170, 2954-2960.

Genigeorgis, C.A. (1989) Present state of knowledge on staphylococcal intoxication. International fournal of Food Microbiology 9, 327-360.

Jarraud, S., Peyrat, M.A., Lim, A., Tristan, A., Bes, M., Mougel, C., Etienne, J., Vandenesch, F. et al. (2001) egc, a highly prevalent operon of enterotoxin gene, forms a putative nursery of superantigens in Staphylococcus aureus. Fournal of Immunology 166, 669-677.

Jones, C.L. and Khan, S.A. (1986) Nucleotide sequence of the enterotoxin B gene from Staphylococcus aureus. Fournal of Bacterio$\log y \mathbf{1 6 6}, 29-33$.

Kvellestad, A., Johansen, G. and Ewald, A. (1988) Hvit geitost stafylokokk matforgiftning (White goat cheese - staphylococcal food poisoning). Norsk Veterincertidsskrift 100, 6, 466-468.

Løvseth, A., Loncarevic, S. and Berdal, K.G. (2004) Modified multiplex PCR method for detection of pyrogenic exotoxin genes in Staphylococcal isolates. Fournal of Clinical Microbiology 42, 3869-3872.

Letertre, C., Perelle, S., Dilasser, F. and Fach, P. (2003) Identification of a new putative enterotoxin SEU encoded by the $\operatorname{egc}$ cluster of Staphylococcus aureus. Fournal of Applied Microbiology 95, 38-43.
Lewis, S.J. and Corry, J.E.L. (1992) Comparison of a cold enrichment and the FDA method for isolating Listeria monocytogenes and other Listeria spp. From ready-to-eat food on retail sale in the U.K. International Fournal of Food Microbiology 12, 281-286.

Loncarevic, S., Tham, W. and Danielsson-Tham, M.-L. (1996) The clones of Listeria monocytogenes detected in food depend on the method used. Letters in Applied Microbiology 22, 381-384.

Loncarevic, S., Danielsson-Tham, M.-L, Mårtensson, L., Ringnér, Å, Runehagen, A. and Tham, W. (1997) A case of foodborne listeriosis in Sweden. Letters in Applied Microbiology 24, 65-68.

McDougal, L.K., Steward, C.D., Killgore, G.E., Chaitram, J.M., McAllister, S.K. and Tenove, F.C. (2003) Pulsed-Field Gel Electrophoresis typing of oxycillin-resistant Staphylococcus aureus isolates from the United States: Establishing a national database. Fournal of Clinical Microbiology 41, 5113-5120.

McLauchlin, J., Narayanan, G.L., Mithani, V. and O'Neill, G. (2000) The detection of enterotoxins and toxic shock genes in Staphylococcus aureus by polymerase chain reaction. Fournal of Food Protection 63, 479-488.

Monday, S.R. and Bohach, G.A. (1999) Use of multiplex PCR to detect classical and newly described pyrogenic toxin genes in staphylococcal isolates. Fournal of Clinical Microbiology 37, 3411-3414.

Munson, S.H., Tremaine, M.T., Betley, M.J. and Welch, R.A. (1998) Identification and characterization of staphylococcal eneterotoxin types G and I from Staphylococcus aureus. Infection and Immunity 66, 3337-3348.

Omoe, K., Hu, D.-L., Takahashi-Omoe, H., Nakane, A. and Shinagawa, K. (2003) Identification and characterization of a new staphylococcal enterotoxin-related putative toxin encoded by two kinds of plasmids. Infection and Immunity 71, 6088-6094.

Orwin, P.M., Leung, D.Y., Donahue, H.L., Novick, R.P. and Schlievert, P.M. (2001) Biochemical and biological properties of Staphylococcal enterotoxin K. Infection and Immunity 166, 4259.

Pereira, M.L., do Carmo, L.S., Dos Santos, E.J., Pereira, J.L. and Bergdoll, M.S. (1996) Enterotoxin H in staphylococcal food poisoning. Fournal of Food Protection 59, 559-561.

Reiser, R.F., Robbins, R.N., Noleto, A.L., Khoe, G.P. and Bergdoll, M.S. (1984) Identification, purification, and some physicochemical properties of staphylococcal eneterotoxin $\mathrm{C}_{3}$. Infection and Immunity 45, 625-630.

Ren, K., Bannan, J.D., Pancholi, V., Cheung, A.L., Robbins, J.C., Fischetti, V.A. and Zabriskie, J.B. (1994) Characterization and biological properties of a new staphylococcal exotoxin. Fournal of Experimental Medicine 180, 1675-1683.

Roberson, J.R., Fox, L.K., Hancock, D.D. and Besser, T.E. (1992) Evaluation of methods for differentiation of coagulase-positive Staphylococci. Journal of Clinical Microbiology 30, 3217-3219.

Rosec, J.P. and Gigaud, O. (2002) Staphylococcal enterotoxin genes of classical and new types detected by PCR in France. International Journal of Food Microbiology 77, 61-70.

$\mathrm{Su}$, Y.C. and Wong, A.C.L. (1995) Identification and purification of a new staphylococcal enterotoxin, H. Applied and Environmental Microbiology 61, 1438-1443.

Zhang, S., Iandolo, J.J. and Stewart, G.C. (1998) The enterotoxin D plasmid of Staphylococcus aureus encodes a second eneterotoxin determination (sej). FEMS Microbiological Letters 168, 227-233. 